\title{
$\mathrm{RHT}$ 기법을 이용한 카울크로스바의 조립위치 결정에 관한 연구
}

\author{
신익상 ${ }^{1} \cdot$ 강동현 $^{1 *} \cdot$ 홍영기 $^{1} \cdot$ 민영봉 $^{2}$ \\ ${ }^{1}$ 국립농업과학원 농업공학부, ${ }^{2}$ 경상대학교 생물산업기계공학과
}

\section{RHT-Based Ellipse Detection for Estimating the Position of Parts on an Automobile Cowl Cross Bar Assembly}

\author{
Ik Sang Shin ${ }^{1}$, Dong Hyeon Kang ${ }^{1}$ *, Young Gi Hong ${ }^{1}$, Young Bong Min ${ }^{2}$ \\ ${ }^{1}$ Dept of Agricultural Machinery, National Academy of Agricultural Science, Suwon, 441-707, Korea \\ ${ }^{2}$ Dept. of Bio-Industrial Machinery Eng., Gyeongsang National University, Jinju, 660-701, Korea
}

(Received: September $5^{\text {th }}, 2011$; Revised: September 20 ${ }^{\text {th }}, 2011$; Accepted: September $26^{\text {th }}, 2011$ )

\section{Abstract}

This study proposed the new method of discerning the assembled parts and presuming the position of central point in a Cowl Cross Bar (CCB) using a Charge-Couple Device (CCD) camera attached to a robot in the auto assembly line. Three control points of an ellipse were decided by three reference points, which were equally distanced. The radii of these reference points were determined by the size of the object, and the repeated presumption secured the precise determination. The comparison of the central point of ellipse presumed by Randomized Hough Transform (RHT) with the part information stored in a database was used for determining the faulty part in an assembly. The method proposed in this study was applied for the real-time inspection of elliptical parts, such as bolt, nut hole and so on, connected to a CCB using a CCD camera. The findings of this study showed that the precise decision on whether the parts are inferior or not can be made irrespective of the lighting condition of industrial site and the noises of the surface of the part. In addition, the defect decision on the individual elliptic parts assembled in a CCB showed more than 98\% accuracy within a 500-millisecond period at most.

Keywords : Inspection system, Cowl cross bar, Randomized hough transform, Ellipse detection

\section{1. 서 론}

최근 컴퓨터 기술의 발달로 의료, 로봇, 보안 분야뿐만 아 니라 거의 대부분의 물체인식이 필요한 분야에서 영상처리가 널리 이용되고 있다. 특히 자동차 등 기계조립라인에서 로봇 과 더불어 효율적인 부품조립과 그 정확성을 높이기 위하여 영상처리 시스템을 이용하는 추세이다. 그러나 현가장치의 골격이 되는 카울크로스바(Cowl Cross Bar, 이하 $\mathrm{CCB})$ 는

*Corresponding author: Dong Hyeon Kang

Tel: +82-31-290-1863; Fax: +82-31-290-1860

E-mail: kang6906@korea.kr
자동차의 성능향상과 안전성 면에서 중요한 역할을 함에도 불구하고, 대부분 검사자의 육안에 의존하고 있는 실정이다. 사람이 검사하는 경우 검사자의 주관과 피로도에 따라 장시 간 동안 부품 검사를 할 수 없을 뿐만 아니라 이로 인해 오차 를 발생시킬 우려가 크다.

이에 비하여 영상처리를 이용한 검사는 이러한 단점들을 극복할 수 있고, 검사의 정확도를 크게 향상시켜 미세한 불량 까지도 검출이 가능하며, 실시간으로 빠르게 검사할 수 있기 때문에 부품검사의 공정시간을 단축할 수 있다. 이와 같이 영 상처리를 이용한 검사시스템은 대표적으로 PCB(Printed Circuit Board)(Choi et al., 2003; Mashohor et al., 2006; Ibrahim and Al-Attas, 2005), IC(integrated circuit) 생산라인(Dom 
and Brecher, 1995; Rajeswari and Rodd, 1999)에 사용되고 있고, 특히 자동차 생산라인에서 자동차의 문틀 공백을 검사하 는데 사용된다(Kosmopoulos and Varvarigou, 2001). 최근에 는 여러 분야에서 $3 \mathrm{D}$ 데이터를 이용한 자동비전검사시스템이 사용되고 있고, 물체의 $\mathrm{CAD}$ 데이터 정보를 이용하는 $3 \mathrm{D}$ 검 사는 많은 제약 조건이 따르지만 검출결과의 정확성이 높은 것으로 보고되고 있다(Bhanu, 1987; Zhang, 2005; Malassiotis and Strintzis, 2003).

그러나 다양한 분야에서 영상처리를 이용한 검사가 활용됨 에도 불구하고 $\mathrm{CCB}$ 의 경우 볼트, 핀, 너트, 홀 등의 크기나 형상이 다른 부분들 때문에 사람이 직접 육안으로 검사하는 실정이다. 따라서 영상처리기법을 적용하여 다양한 형상의 부분들에 대한 정확한 위치 검출이 필요하다. 관련된 연구로 서 Hough(1962)가 제안한 Hough Transform(이하 HT)은 타 원 성분을 검출하는데 매우 유용한 방법이다. HT는 잡음에 강 하며 정확도가 좋지만, 모델변수에 대응되는 배열(accumulator array) 크기에 의존하기 때문에 복잡한 영상에서 처리시간이 급속히 증가하는 단점이 있다. Xu(1990)는 이 단점을 보안하 기 위해 HT를 최적화 한 Randomized Hough Transform(이 하 RHT)을 제안하였다. RHT는 계산 시간을 줄이기 위해 배 열의 수를 줄여 검사 수행시간과 정확도를 향상시켰다. 그러 나 영상에서 타원을 결정하기 위해서는 3개의 컨트롤 포인트 (control points)가 필요하고, 검출된 엣지 영상 내에서 이 포 인트를 임의로 선택하기 때문에 복잡한 영상처리에서 정확도 및 처리속도 저하의 문제점을 가지고 있다. Fung 등(1996)은 RHT와 Generalized HT(GHT)을 결합한 RGHT 알고리즘을 제 안하였고, 임의의 크기를 가지는 영상에 대해 적은 배열공간으로 빠른 속도와 정확성을 높이는 장점을 가지고 있다. Cheng과 $\operatorname{Liu}(2004)$ 는 RHT보다 속도와 성능 개선을 위해 엣지 영상을 레이블링하여 두 원의 겹치는 점을 찾고, 두 개의 노드로 나눠 RHT를 적용하였다. 이 알고리즘은 타원의 임의의 3점을 노드 를 통해 쉽게 찾을 수 있기 때문에 속도와 정확도를 향상시켰지 만, 두 원의 겹치는 포인트를 정확히 찾아야 하는 단점이 있다.

본 연구에서는 자동차 조립부품 중 $\mathrm{CCB}$ 에 고정되는 볼트, 너트, 홀 등의 정확한 조립위치를 판별하는 개선된 RHT 알고 리즘을 제시하고 검사 시스템을 구현하였다. $\mathrm{CCB}$ 검사 시스 템은 그 정확성과 빠른 판별이 필요하기 때문에 기계시각을 이용하여 고정된 볼트위치, 너트의 기울기, 그리고 홀의 위치 를 판별하였고, 부품정보 $\mathrm{DB}$ 에 입력된 각 파트의 $\mathrm{CAD}$ 정보
와 비교하여 불량 유무를 판별하였다. 전처리 과정으로 실제 조립 현장의 조명조건 및 외부간섭에 따른 노이즈는 제거하 였고, 부품의 중심위치는 세그먼트 그룹화를 적용하여 추적하 였다. 또한 정확한 타원의 중심점을 찾기 위해 부품의 크기에 따라 유연하게 결정되는 세 개의 제어 포인트인 Flexible and Rotating Control Points는 RHT에 적용되었다.

\section{2. 재료 및 방법}

\section{가. 카울크로스바}

$\mathrm{CCB}$ 는 자동차 앞좌석에 부착되는 커버링부, 기계부, 컨트 롤부 등을 안정적으로 고정하는데 필요한 핵심부품이다. 또 한 자동차가 주행 중이거나 정차 시 steering wheel의 떨림을 방지하고, 충돌 시 충격에너지를 흡수하는 역할을 한다. $\mathrm{CCB}$ 의 조립 후 정밀검사는 안전한 주행을 위해 필수적이다. 일반 적으로 $\mathrm{CCB}$ 는 그림 1 과 같이 일반형(Left Hand Drive type),

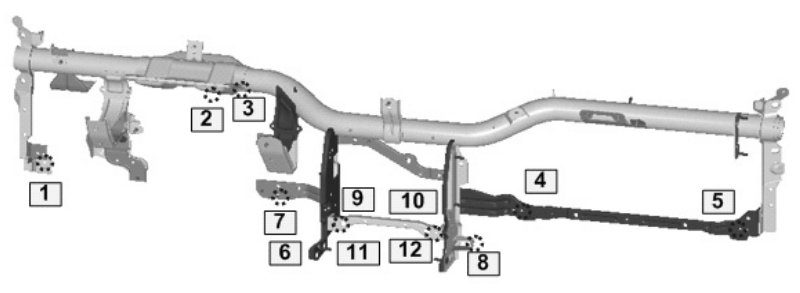

(a) Common type

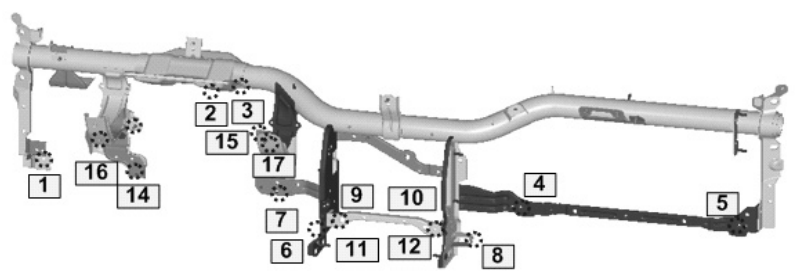

(b) North America type

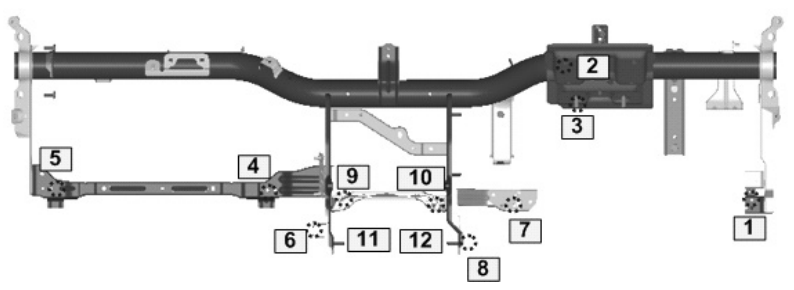

(c) RHD type

Fig. 1 CCB Models.

Table 1 Check list of inspection points for $\mathrm{CCB}$

\begin{tabular}{c|c|c|c}
\hline Check Point & Check List & Check Point & Check List \\
\hline $1,7,9$ & Pad main core assembly of the parts & 6,8 & Mounting \\
\hline 2,3 & Column shaft assembly of the parts & 11,12 & Pin \\
\hline 4,5 & Box contracting parts & $13 \sim 15$ & Bolt \\
\hline
\end{tabular}


북미형(North america type), 오른쪽 핸들형(Right Hand Drive type)등 3 가지 형태의 모델이 있는데, 각 모델마다 검사 부 위가 달라 검사자의 육안을 통해서 불량을 검출한다. 검사항 목은 홀, 볼트, 너트, 핀 등 4가지이며, 표 1은 각 부위에 대한 필수 검사 항목을 나타낸 것이다.

\section{나. 조립위치 검출 알고리즘}

본 연구에서 제안한 $\mathrm{CCB}$ 검사는 크게 전처리, 세그먼트 그룹화(segment clustering), RHT를 이용한 타원 중심 검출 과정으로 나뉘는데, 그 처리의 흐름은 그림 2 와 같다. 전처리 는 생산현장에서 입력된 신호의 영상 잡음을 $\mathrm{HF}$ 법을 이용하 여 제거하고 엣지를 검출하여 라벨링하는 과정이다. 세그먼 트 그룹화는 필터링 된 입력 영상으로부터 검사 부위의 엣지 를 추출한 후 라벨링하여 각 부분에 속하는 영역을 병합해 주는 과정이다. 타원 중심 검출은 검사 부위의 중심점을 정확 하게 판정하기 위해 flexible and rotating control point들을 RHT에 적용시켜 중심점을 검출하는 과정이다.

\section{1) Homomorphic Filter(HF)을 이용한 전처리과정}

일반적으로 부품 조립 공정은 조명이 설치된 실내 환경에 서 이루어지는데, 이러한 작업 환경에서의 불균일한 조명은 조명에 의한 반사 및 저주파 잡음 등을 발생시켜 검사 부분 의 식별을 어렵게 만든다. 본 연구에서는 전처리 과정에서 푸 리에변환을 기반으로 영상의 저주파 잡음을 감소시키는 $\mathrm{HF}$ 를 사용하였다. 이 필터는 고주파 성분을 보상하여 영상의 명 암대비를 향상시킬 수 있고, 금속 재질의 부품에 의한 반사성 분을 효율적으로 제거할 수 있다는 장점이 있다.

$\mathrm{HF}$ 법은 영상 $f(x, y)$ 를 물체로부터 반사된 빛에 의해 형성 되며 조명의 조도 $i$ 와 반사율 $r$ 의 곱의 형태로 표현할 수 있 다(식 (1)).

$$
f(x, y)=i(x, y) r(x, y)
$$

여기서, 조도 $i$ 는 일반적으로 일정하거나 변화가 적은데 비 하여 반사율 $r$ 은 부품의 종류와 형태에 따라 크게 변한다. 식 (2)와 (3)은 $\mathrm{HF}$ 를 $\log$ scale의 입력 영상 $\mathrm{Z}$ 에 적용하여 필터 링된 영상 $\mathrm{S}$ 를 출력함을 나타내는 것이다.

$$
\begin{aligned}
S(u, v) & =H(u, v) Z(u, v) \\
& =H(u, v) F_{i}(u, v)+H(u, v) F_{r(u, v)} \\
H(u, v) & =\left(\gamma_{H}-\gamma_{L}\right)\left[1-e^{-c\left(D^{2}(u, v) / D_{0}^{2}\right)}\right]+\gamma_{L}
\end{aligned}
$$

여기서, $F_{i}$ 는 조명 성분, $F_{r}$ 은 반사 성분, $\mathrm{H}$ 는 $\mathrm{HF}, \mathrm{D}_{0}$ 는 중 심으로부터의 거리, $D(u, v)$ 는 필터된 영상의 중심으로부터 의 거리를 나타낸다. 또한 사용된 매개변수 $\gamma_{H}, \gamma_{L}$ 은 실험을 통해 구해진 값 들이며, 각각 $0.65,1.2$ 가 적용되었다. $\mathrm{HF}$ 로 필터링된 영상은 그림 2와 같이 median filter를 이용하여 한 번 더 필터링 된 후, sobel edge detector로 영상의 경계값 (boundary value)을 구하고 라벨링하여 각각의 세그먼트를 검출한다.

\section{2) 세그먼트 그룹화}

전처리 과정을 거쳤음에도 불구하고 실제 영상에서는 불필 요한 잡음 성분들과 단일 물체로부터 분리된 다수의 세그먼 트들이 존재하게 된다. 본 연구에서는 한 개의 타원 영역에 속하는 세그먼트를 찾기 위해 세그먼트 그룹화 방법을 이용 하였다. 세그먼트 그룹화는 한 영역에 속하는 분할된 세그먼 트들을 병합하고 기타 나머지 부분들은 제거하는 방법으로 검사 항목이 홀이나 너트인 경우에는 타원 영역으로 나타나 지만, 볼트의 경우엔 타원 영역이 분할되어 나타나기 때문에 분할된 부분의 병합이 필요하다.

본 연구에서는 다음과 같은 방법으로 세그먼트 그룹화를 수행하였다.

(1) 전처리 과정에서 획득된 세그먼트들의 영역 크기를 각각 계산하고, 기준값(threshold)보다 적은 영역들은 잡음으 로 판별, 제거한다.

(2) 필터링된 모든 세그먼트들의 중심점을 구한 후, 라벨링 된 영역의 크기가 검사 대상과 유사하고 세그먼트의 좌 표가 전체 영상의 중심좌표에 가장 가까운 세그먼트를 선택한다.

(3) 선택된 세그먼트의 중심점과 나머지 세그먼트들 간의 중 심점거리가 기준값 이하이면 병합하고 이상이면 제거한 다(식 (4)).

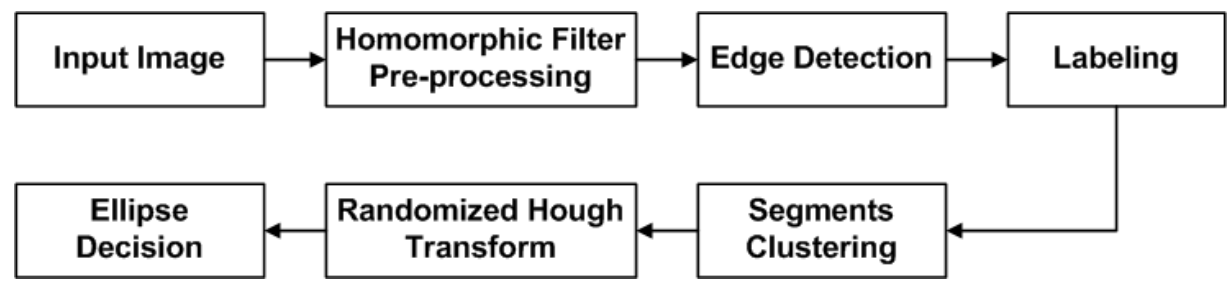

Fig. 2 Flow chart of the whole processing for the detecting system. 


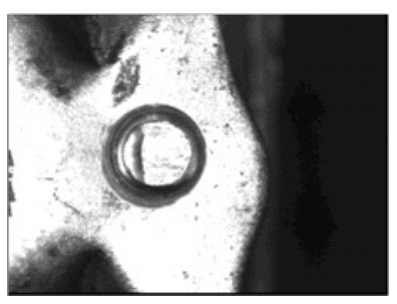

(a)

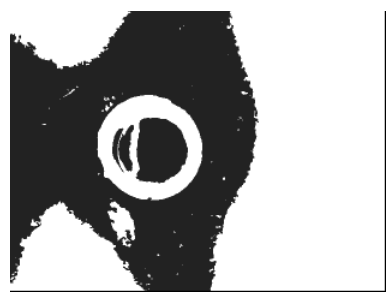

(c)

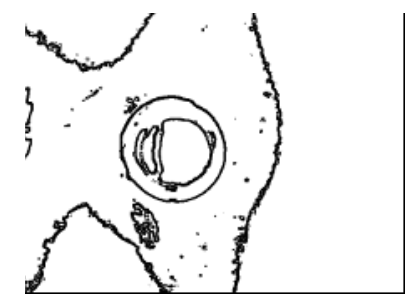

(b)

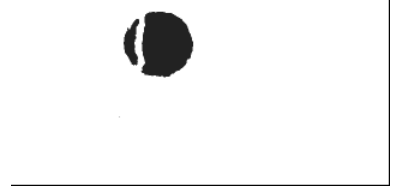

(d)

Fig. 3 Images of each step of segment clustering.

(a) The captured image with CCD camera

(b) The image generated by sobel edge detector

(c) The image after labeling

(d) The final image of segment clustering

$$
S_{r}=\sum_{i=1}^{s_{n}} \operatorname{Distance}(i)
$$

$$
\text { Distance }(i)=\left\{\begin{array}{l}
1 \text { if } \overline{P_{0} P a}<T_{h} \\
0 \text { otherwise }
\end{array}\right.
$$

여기서, $\mathrm{S}_{\mathrm{r}}$ 은 병합된 세그먼트, $\mathrm{S}_{\mathrm{n}}$ 은 병합되지 않은 총 세그 먼트 수, $\overline{P_{0} P_{a}}$ 는 처음 선택한 세그먼트의 중심점 $P_{0}$ 에서 임 의의 세그먼트의 중심점 $P_{a}$ 까지의 거리를 나타낸다. 기준값 $T_{h}$ 는 다양한 볼트 영상에 대하여 병합조건을 만족시키도록 실험적으로 결정하였다. 그림 3은 전처리 과정부터 세그먼트 그룹화 과정까지의 영상을 나타낸 것이다.

\section{3) 조립위치 검출법}

RHT는 영상에서 선, 타원 또는 원 등의 곡선 세그먼트들 을 찾는 방법이다. RHT를 이용하여 타원을 검출하기 위해서 는 식 (5)에서와 같이 5 개의 매개변수가 필요하다. 식 (6)의 부등식을 만족하는 경우, 식 (5)는 타원의 방정식이 된다.

$$
\begin{aligned}
& a(x-p)^{2}+2 b(x-p)(y-q)^{2}+c(y-q)^{2}=1 \\
& a c-b^{2}>0
\end{aligned}
$$

식 (5)와 식 (6)을 이용할 경우, 5개의 매개변수를 계산해 야 하기 때문에 많은 메모리와 계산 시간이 소요된다. 이를 개선하기 위해 Rajeswari와 Rodd(1996)는 타원의 기하학적 특성을 이용하여 중심점을 결정하고, 매개변수의 수를 줄임 으로써 계산 속도를 향상시켰다. 결과적으로 타원에 속하는

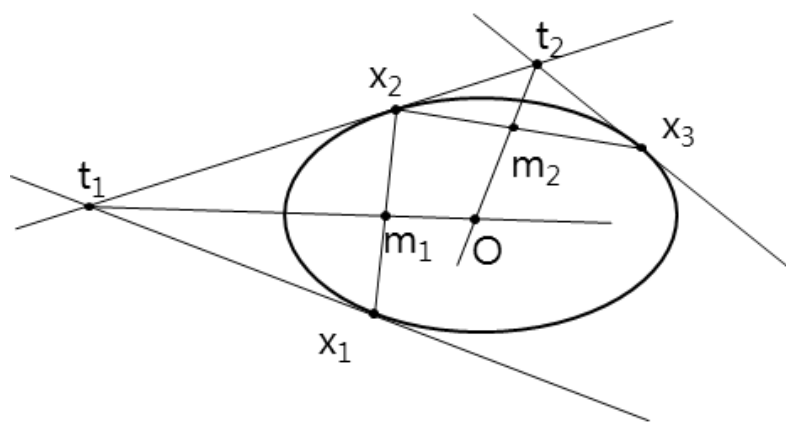

Fig. 4 Decision of the center point for an ellipse.

매개변수를 결정하는 것은 타원의 중심점 결정과 나머지 3 개 의 매개변수를 찾는 것으로 귀착된다.

그림 4 와 같이 타원의 중심을 찾기 위해 타원 위의 임의의 세 점 $\mathrm{X}_{1}, \mathrm{X}_{2}, \mathrm{X}_{3}$ 을 선택하고, 두 점 $\mathrm{X}_{1}, \mathrm{X}_{2}$ 에서의 접선이 만 나는 교차점 $\mathrm{t}_{1}$ 과 두 점을 잇는 직선의 중심점 $\mathrm{m}_{1}$ 을 찾는다. 다른 두 점 $\mathrm{X}_{2}, \mathrm{X}_{3}$ 를 이용하여 동일한 과정을 통해 $\mathrm{t}_{2}$ 와 $\mathrm{m}_{2}$ 를 얻을 수 있고, 이렇게 구해진 $\mathrm{t}_{1}$ 과 $\mathrm{m}_{1}, \mathrm{t}_{2}$ 와 $\mathrm{m}_{2}$ 를 잇는 직선들 이 교차하는 교차점이 타원의 중심임을 알 수 있다. 따라서 RHT를 이용하여 타원을 추정하는 경우에는 임의의 세 점 $\mathrm{X}_{1}, \mathrm{X}_{2}, \mathrm{X}_{3}$ 을 어떻게 선택하는가가 중요한 관건이 된다.

식 (5)의 $\mathrm{p}, \mathrm{q}$ 는 추정된 타원의 중심점이 되고, 이점을 원점 으로 평행이동 시키면 식 (7)과 같이 표현된다. 이 타원의 방 정식은 임의의 세 점 $\mathrm{X}_{1}, \mathrm{X}_{2}, \mathrm{X}_{3}$ 를 만족해야 하므로, 식 (8)과 같이 나타낼 수 있고, 결국 매개변수 $\mathrm{a}, \mathrm{b}, \mathrm{c}$ 는 이 연립방정식 을 풀면 구할 수 있다.

$$
\begin{aligned}
& a x^{2}+2 b x y+c y^{2}=1 \\
& {\left[\begin{array}{ccc}
x_{1}^{2} & 2 x_{1} y_{1} & y_{1}^{2} \\
x_{2}^{2} & 2 x_{2} y_{2} & y_{2}^{2} \\
x_{3}^{2} & 2 x_{3} y_{3} & y_{3}^{2}
\end{array}\right]\left[\begin{array}{l}
a \\
b \\
c
\end{array}\right]=\left[\begin{array}{l}
1 \\
1 \\
1
\end{array}\right]}
\end{aligned}
$$

전술한 바와 같이 RHT를 이용한 타원의 검출 방법에서는 임의의 세 점을 어떻게 선택하는가가 중요하다. 따라서 부품 의 크기에 따라 세 점(control points)을 유연하게 결정할 수 있도록 flexible and rotating control points를 이용하여 세 점 을 결정하고 이를 RHT에 적용하였다. 제안된 알고리즘은 다 음과 같다.

Step 1. 라벨링을 통해 구해진 하나의 세그먼트를 선택하고 임의의 무게중심 $\mathrm{O}$ 점을 구한다.

Step 2. 구해진 $\mathrm{O}$ 점을 기준으로 세그먼트의 경계값을 포함 하는 지점에 임의의 한 점 $\mathrm{C}_{1}$ 을 선택한다.

Step 3. 직선 $\mathrm{OC}_{1}$ 을 $\mathrm{O}$ 점을 기준으로 120 도씩 2회 회전시켜 두 점 $\mathrm{C}_{2}, \mathrm{C}_{3}$ 을 결정한다.

Step 4. 결정된 세 점 $\mathrm{C}_{1}, \mathrm{C}_{2}, \mathrm{C}_{3}$ 의 좌표값을 무게중심 $\mathrm{O}$ 로 
접근시키는 과정에서 세그먼트의 경계값과 교차하 는 점 $\mathrm{P}_{1}, \mathrm{P}_{2}, \mathrm{P}_{3}$ 을 구한다. 이 점들을 rotating control point라 한다.

Step 5. 구해진 세 점 $\mathrm{P}_{1}, \mathrm{P}_{2}, \mathrm{P}_{3}$ 을 RHT에 적용하여 중심점 $\mathrm{C}$ 를 계산하고, 중심점 $\mathrm{C}$ 의 좌표값을 배열로 저장한다.

Step 6. O점을 기준으로 시계방향으로 1 도 증가시켜 $\mathrm{C} 1, \mathrm{C} 2$, $\mathrm{C} 3$ 값을 새로 결정하고, step 4, 5를 120회(120도 회 전) 반복 수행한다.

Step 7. 저장된 배열 값들 중 가장 많은 빈도수를 나타내는 좌표값을 타원의 중심점으로 결정한다.

이렇게 구해진 중심점은 $\mathrm{DB}$ 형태로 저장된 설계도면의 각 부분들의 중심점과의 오차를 구하는데 사용한다.

\section{다. 시험장치}

$\mathrm{CCB}$ 검사 시스템은 크게 로봇제어와 영상처리 두 부분으 로 나뉜다. 로봇제어 부분은 6 자유도 로봇과 로봇 제어기로 구성되는데, 6 자유도 로봇은 검사자가 원하는 위치로 정확 하게 이동할 수 있도록 해 줄 뿐만 아니라, 다양한 각도에서 영상을 수집할 수 있도록 해 준다. 로봇제어기는 컴퓨터와 $\mathrm{RS} 232$ 로 통신하고, 로봇의 이동 오차는 최대 $5 \mathrm{~mm}$ 이다. 영 상처리 부분은 영상수집을 위한 $\mathrm{CCD}$ 카메라, frame grabber, 영상처리를 위한 컴퓨터로 구성되었다. 카메라는 $640 \times 480$ 의 분해능과 $12.27 \mathrm{~Hz}$ 로 영상수집이 가능한 모델을 사용하였고, 6 자유도 로봇의 끝단(end effector)에 부착하여 검사에 필요 한 영상을 수집하였다. 또한 카메라의 조명은 흰색 LED 램 프를 부착하여 부품 표면의 조명을 적절히 유지하도록 하였 다. $\mathrm{CCB}$ 를 검사 테이블에 놓으면 로봇은 미리 주어진 경로 를 따라 검사 부위로 이동하고 카메라를 통해 2 차원 영상을

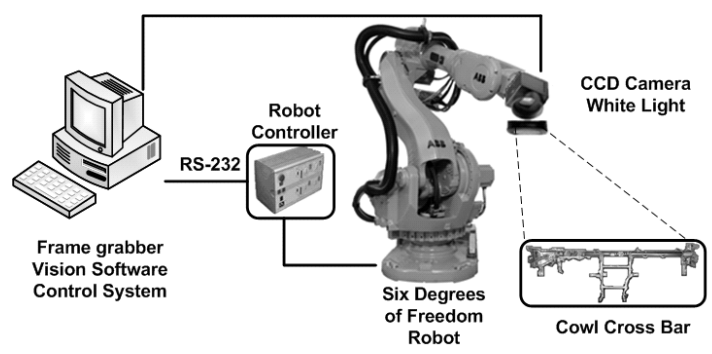

Fig. 5 Configuration of the detecting system.

Table 2 Specifications of the robot

\begin{tabular}{l|l}
\hline \multicolumn{1}{c|}{ Item } & \multicolumn{1}{c}{ Specification } \\
\hline Model & $\mathrm{KR} \mathrm{16}$ \\
\hline Degrees of freedom & 6 \\
\hline Payload & $6 \mathrm{~kg}$ \\
\hline Dimensions of arm & $1184 \times 1030 \times 1078\left(\mathrm{~L}_{1} \times \mathrm{L}_{2} \times \mathrm{L}_{3}, \mathrm{~mm}\right)$ \\
\hline
\end{tabular}

수집한다. 그림 5 는 검사 시스템의 전체 구성을 나타낸 것이 고, 표 2 는 시험에 사용된 로봇의 제원을 나타낸 것이다.

\section{라. 시험 방법}

시험은 제안된 알고리즘을 전술한 3 가지 형태의 $\mathrm{CCB}$ 모델 에 대하여 볼트, 너트, 홀, 핀 등 4가지 항목에 대해 실시하였 다. 시험에 사용된 $\mathrm{CCD}$ 카메라의 해상도는 $640 \times 480$ 이고, 한 픽셀당 $0.1 \mathrm{~mm}$ 가 측정되도록 보정하여 타원의 중심 검출 시 험과 $\mathrm{CAD}$ 도면 좌표를 이용한 위치 검출 시험을 실시하였다.

\section{1) 타원 중심점 검출 시험}

제안된 알고리즘을 이용하여 전술한 4가지 항목에 대한 타 원의 중심위치를 검출하기 위한 시험은 로봇을 수동조작을 통하여 카메라를 검출하고자하는 정확한 위치에 이동시킨 후 영상을 획득하여 중심점 위치를 검출하였다. 검출된 중심점 은 $\mathrm{CAD}$ 도면의 좌표와 비교하여 오차가 $2 \mathrm{~mm}$ 이하일 때 정확히 검출한 것으로 간주하였다. 시험은 각각 50 회 반복하 여 실시하였다.

\section{2) 자동조작을 통한 중심점 검출시험}

각 모델들은 15 개 이하의 검사 부위를 갖고 있으며, $\mathrm{CAD}$ 도면을 통해 검사 부위에 대한 정확한 위치를 알 수 있기 때 문에 로봇의 이동 경로를 미리 결정할 수 있다. 6 자유도 로 봇을 이용하여 그 끝단에 달린 카메라를 정해진 위치로 이동 시켜 원하는 영상을 수집하고 알고리즘에 적용하여 시험을 실시하였다. 로봇의 이동오차가 최대 $5 \mathrm{~mm}$ 임을 감안하여 최대 $7 \mathrm{~mm}$ 이내로 입체적 거리 차가 나타나면 결함이 없는 것으로 판정하였다. 시험은 한 부품 당 최대 $500 \mathrm{~ms}$ 내에 검 사가 이루어지며, 로봇의 이동시간을 제외하면 각모델의 15 개 내외 부품에 대해 최대 약 6.98 초의 시간이 소요된다. 시 험은 각각 3 회 반복하여 실시하였다.

\section{3. 시험결과}

\section{가. 타원 중심점 검출 시험}

제안된 알고리즘을 이용하여 각 검사 항목별 타원 검출 결 과는 그림 6과 같다. 각 항목에 대하여 타원은 정확하게 검출 되었다. 특히 그림 6-(d)는 검사 항목 주변에 잡음이 존재하 고 세그먼트도 분리가 되어 있음에도 불구하고 정확하게 타 원을 검출하였다. 표 3 은 $\mathrm{CCB}$ 모델들의 타원 검출에 대한 수행 시간, 정확도 그리고 중심점 좌표의 최다 빈도수를 나타 낸 것이다. 작업 수행시간은 약 $500 \mathrm{~ms}$ 이하였으며, 정확도 는 북미 모델(그림 1 의 b)의 볼트를 제외한 모든 조건에서 오 차범위가 $2 \mathrm{~mm}$ 이하로 결함이 없는 것으로 조사되었다. 북 
Table 3 Results of detecting the central point of ellipse with respect to each model

\begin{tabular}{c|c|c|c|c}
\hline Model & Parts & Processing Avg. Time (msec) & Accuracy (\%) & Avg. Max point \\
\hline \multirow{3}{*}{ Common } & Hole & 493 & 100 & 34 \\
\cline { 2 - 5 } & Pin & 266 & 100 & 22 \\
\cline { 2 - 5 } & Nuts & 487 & 100 & 34 \\
\hline \multirow{3}{*}{ North America } & Hole & 493 & 100 & 22 \\
\cline { 2 - 5 } & Pin & 266 & 100 & 25 \\
\cline { 2 - 5 } & Nuts & 487 & 98 & 12 \\
\hline \multirow{5}{*}{ RHD } & Bolt & 468 & 100 & 34 \\
\cline { 2 - 5 } & Hole & 493 & 100 & 22 \\
\cline { 2 - 5 } & Pin & 266 & 487 & 25 \\
\hline
\end{tabular}

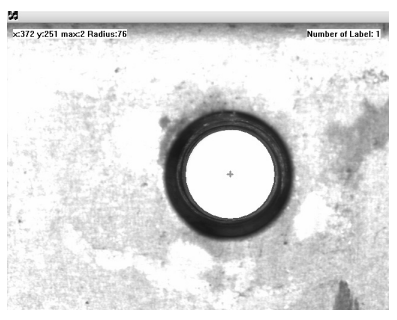

(a)

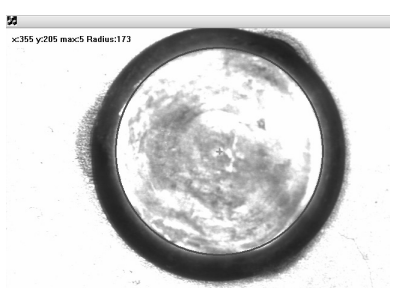

(c)

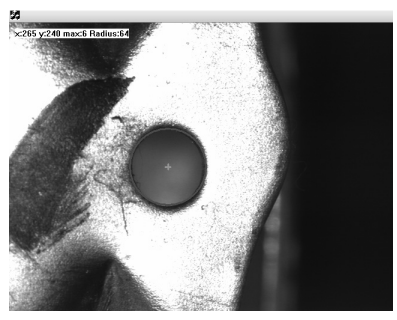

(b)

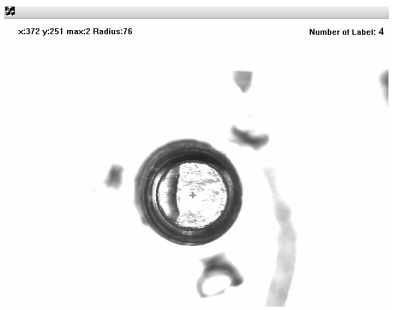

(d)
Fig. 6 Results of detecting ellipse (a) nut (b) hole (c) pin (d) bolt with separated segments.

미 모델의 경우 다른 항목들과는 달리 볼트의 정확도가 $98 \%$ 로 다소 떨어지는 것으로 나타났고, 검출된 중심점의 최대 빈 도수 또한 평균 12회로 다른 항목에 비하여 낮은 것으로 조 사되었다. 이는 볼트헤드의 굴곡으로 인하여 잡음이 심하기 때문에 발생하는 문제로 판단된다.

\section{나. 자동조작을 통한 중심점 검출시험}

그림 7은 결함판정을 위해 $\mathrm{DB}$ 중심점과 검출 중심점의 입 체적 거리 차의 예를 나타낸 것이다. $\mathrm{DB}$ 형태로 저장된 검사 부위의 중심점과 검출된 중심점 사이의 입체적 거리 차를 측 정한 결과 각각 $5 \mathrm{~mm}, 6.3 \mathrm{~mm}$ 이었다. 이는 로봇의 동작오 차로 인한 오차와 알고리즘에 의한 오차가 포함되는 최대 7 $\mathrm{mm}$ 이하로 결함이 없는 것으로 판단할 수 있으며, 로봇의 동 작오차를 줄인다면 정확도는 더욱 높아질 것으로 판단된다.

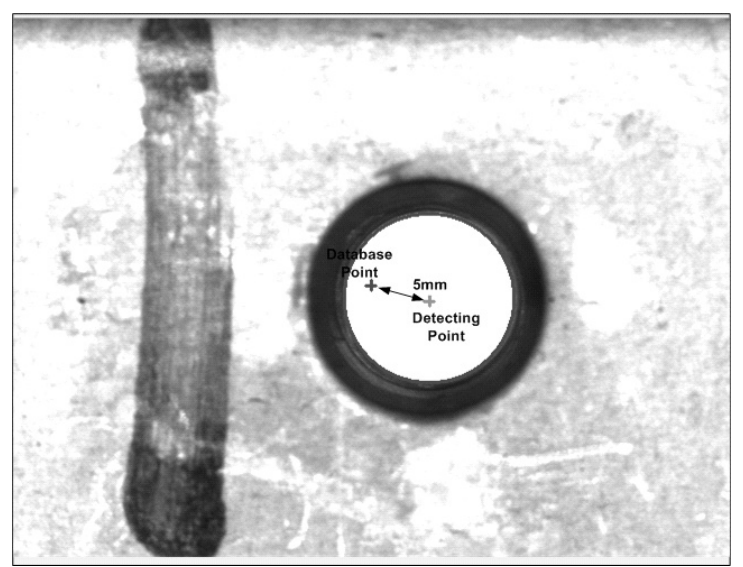

(a)

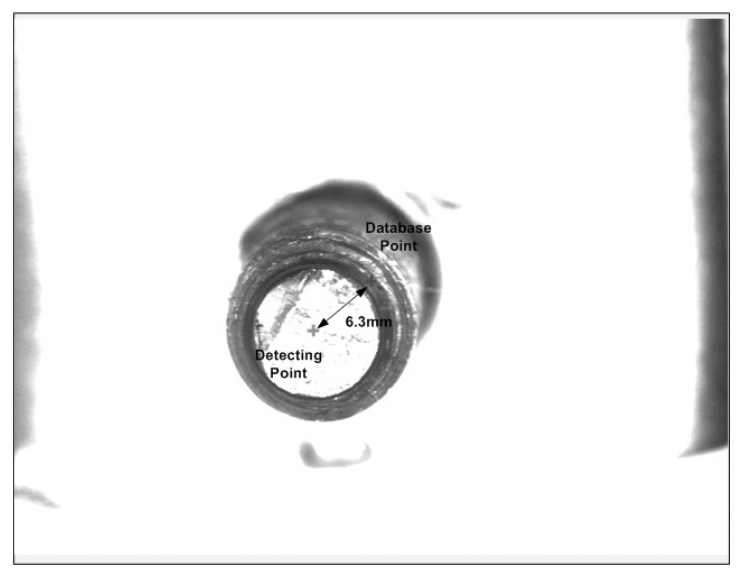

(b)

Fig. 7 Distance between the central point in the DB and that of the detected.

(a) In case of nut (error $=5 \mathrm{~mm}$ ), (b) In case of bolt (error $=6.3$ $\mathrm{mm}$ )

\section{4. 결 론}

본 연구는 효율적인 부품조립과 정확성을 높이기 위하여 영상처리기법을 이용한 $\mathrm{CCB}$ 의 불량 부품 판정 방법을 제시 
하기 위하여 수행한 결과를 요약하면 다음과 같다.

(1) 전처리 과정에서 Homomorphic Filter를 적용하여 저주 파 잡음을 제거하고 영상에서 한 영역에 속하는 세그먼 트를 병합하기 위한 세그먼트 그룹화를 수행하였다.

(2) 기존 RHT방법과는 달리 flexible and rotating control points을 RHT에 적용하여 타원을 빠르고 효율적인 검 출이 가능하였다.

(3) 실험에 의해 물체표면에 발생되는 다양한 잡음과 불균 일한 조명 조건 하에서도 다양한 부품에 대해 정확하 게 부품의 중심점을 추정할 수 있었다. 제안된 방법은 검사 과정에서 극소수 영상이 훼손되어 불량 판별이 어려운 것을 제외하면 산업현장에서 높은 정밀도로 불 량품을 효과적으로 선별 할 수 있는 것으로 나타났다.

\section{참 고 문 헌}

1. Bhanu, B. 1987. CAD-based robot vision. Computer. 20(8): 12-16.

2. Cheng, Z. and Y. Liu. 2004. Efficient technique for ellipse detection using restricted randomized hough transform. Proc. of the International Conference on Information Technology. 2:714-718.

3. Choi, K. S., J. Y. Pyun, and N. H. Kim. 2003. Real-time inspection system for printed circuit boards. Lecture Notes in Computer Science. 2781:458-465.

4. Dom, B. E. and V. Brecher. 1995. Recent advances in the automatic inspection of integrated circuits for pattern defects. Machine Vision and Applications. 8(1):5-19.
5. Fung, P. F., W. S. Lee, and I. King. 1996. Randomized generalized hough transform for 2-D gray scale object detection. Proc. of the 13th International Conference on Pattern Recognition. 2(5):511-515.

6. Hough Paul, V. C. 1962. Methods and means for recognizing complex patterns. U.S. Patent Publication. 3069654.

7. Ibrahim, Z. and S. A. R. Al-Attas. 2005. Wavelet-Based printed circuit board inspection system. Integrated Computer-Aided Engineering. 12(2):201-213.

8. Kosmopoulos, D. and T. Varvarigou. 2001. Automated inspection of gaps on the automobile production line through stereo vision and specular reflection. Computers in Industry. 46(1): 49-62.

9. Malassiotis, S. and M. G. Strintzis. 2003. Stereo vision system for precision dimensional inspection of 3D holes. Machine Vision and Applications. 15(2):101-113.

10. Mashohor, S., J. R. Evans, and A. T. Erdogan. 2006. Automatic hybrid genetic algorithm based printed circuit board inspection. Proc. of the First NASA/ESA Conference on Adaptive Hardware and Systems. 390-400.

11. Rajeswari, M. and M. G. Rodd. 1996. Wire-bond inspection in IC assembly. Proc. SPIE. 2665:186-196.

12. Rajeswari, M. and M. G. Rodd. 1999. Real-time analysis of an IC wire-bonding inspection system. Real-Time Imaging. 5(6):409-421.

13. Xu, L., E. Oja and P. Kultanen. 1990. A new curve detection method: Randomized Hough Transform (RHT). Pattern Recognition Letters. 11(5):331-338.

14. Zhang, Y. 2005. Automatic inspection of industrial sheetmetal parts with single non-metric CCD camera. Advanced Data Mining and Applications. 3584:654-661. 